\title{
EVALUATION OF FUNCTIONAL OUTCOME IN MANAGEMENT OF FRACTURE SHAFT FEMUR IN CHILDREN BY ELASTIC NAILS
}

\author{
Ananthula Ajay', V. V. Narayana Rao ${ }^{2}$
}

${ }_{1}^{1}$ Assistant Professor, Department of Orthopaedics, Guntur Medical College, Guntur, Andhra Pradesh, India.

2I/C Professor, Department of Orthopaedics, Guntur Medical College, Guntur, Andhra Pradesh, India.

\section{BACKGROUND}

ABSTRACT

Treatment for femoral diaphyseal fractures in the age group of 4 - 16 years is controversial. ${ }^{1}$ In recent years, fixation with flexible intramedullary (TENS) nails has become a popular technique $2,3,4,5,6$ for stabilising femur fractures in children.

\section{MATERIALS AND METHODS}

We conducted a prospective observational study in 30 children with femoral shaft fractures treated by TENS. Two nails were inserted in a retrograde manner from medial and lateral entry points above the distal physis. Postoperatively, all the patients were followed for a period of 24 weeks between March 2012 and Feb 2016 at Govt. General Hospital, Guntur. The mean age was 9.6 years (range 4-16 years) and mean hospital stay was 7 days (range 6-10 days). All fractures were radiographically united at a mean of 12.1 weeks (range 6-18 weeks). No angular deformity was observed and followed up until 24 weeks.

\section{RESULTS}

Final outcomes were classified as excellent, satisfactory or poor according to the Flynn scoring criteria for elastic flexible nail fixation. In the present study the final outcome was excellent in $18(60 \%)$ cases, satisfactory in $12(40 \%)$ cases and there were no poor outcome cases.

\section{CONCLUSION}

We conclude that elastic stable intramedullary nailing technique is an ideal method for treatment of paediatric femoral diaphyseal fractures. It gives elastic mobility which promotes rapid union at fracture site and stability which is ideal for early mobilisation.

\section{KEY WORDS}

Fracture Shaft Femur, Elastic Nails, Outcome, Flynn Scoring, Complications.

HOW TO CITE THIS ARTICLE: Ajay A, Rao VVN. Evaluation of functional outcome in management of fracture shaft femur in children by elastic nails. J. Evolution Med. Dent. Sci. 2018;7(33):3703-3705, DOI: 10.14260/jemds/2018/831

\section{BACKGROUND}

After acute infections, trauma is a leading cause of morbidity and mortality in children. Femoral shaft fractures account for $1-2 \%$ of all paediatric fractures.

Femoral fracture is about 2.5 times more common in boys than in girls. Patients with a femoral shaft fracture usually have a history of fall or a motor vehicle accident. In recent years, fixation with flexible intramedullary nails have become popular technique for stabilising femur fracture in children. In the age limit of 4 - 16 years, intraarticular fractures of femur were excluded. Femoral fractures in children were typically stabilised with two nails inserted in a retrograde manner from medial and lateral entry points above the distal physis.

This technique offers several advantages. TENS is a simple, effective and minimally invasive technique. It gives stable fixation $7,8,9$ with rapid healing and prompt return of child to normal activity without any limb length discrepancy. Technique of insertion being close to the fracture haematoma

'Financial or Other Competing Interest': None.

Submission 20-09-2017, Peer Review 09-06-2018,

Acceptance 16-06-2018, Published 13-08-2018.

Corresponding Author:

Dr. Ananthula Ajay,

H. No. 8-6-28/1,

Nehrunagar $5^{\text {th }}$ Lane,

Guntur-522001,

Andhra Pradesh, India.

E-mail: ananthula2009@gmail.com

DOI: $10.14260 /$ jemds/2018/831 is preserved and with very minimal risk of infection, ${ }^{10}$ damage to the growth plate is almost negligible. Flexibility of the nails provide dynamic controlled motion at the fracture site, which stimulates periosteal callus formation. Nails are load sharing implants and allow early mobilisation and weight bearing.

\section{MATERIALS AND METHODS}

In our prospective observational study, we have taken 30 children with diaphyseal femoral fractures who are admitted in govt. General hospital, Guntur, between March 2012 and Feb 2016 after obtaining their consent. Femoral fractures in children are typically stabilised with two nails inserted in a retrograde manner from medial and lateral entry points above the distal physis of femur. Postoperatively, all the patients were followed for a period of 24 weeks. Results were analysed by both clinical and radiological.11,12,13

\section{Inclusion Criteria}

Femoral diaphyseal fractures in children aged between $4-16$ yrs.

\section{Exclusion Criteria}

a. Fractures with intraarticular extension.

b. Gustilo-Anderson grade 2 and 3 compound fractures.

c. Associated co-morbid conditions making the patient unfit for surgery.

\section{Study Design}

Prospective Observational Study. 


\section{RESULTS}

\section{Study Design}

Prospective observational study on 30 children with femoral diaphyseal fractures was undertaken to evaluate the outcome of Titanium elastic nails fixation in paediatric femoral shaft fractures.

\section{Age Distribution of Patients Studied}

4 - 8 yrs. 13 patients (43.3\%), 9 - 12 yrs. 7 patients (23.3\%), $13-16$ yrs. 10 patients (33.3\%).

\section{Mode of Injury of Patients Studied}

RTA 16 patients (53.3\%), fall 11 patients (36.7\%) and fall from height 3 patients $(10 \%)$.

\section{Time for Union}

24 patients $(80 \%)<8-12$ weeks, 6 patients $(20 \%)>12-18$ weeks.

\begin{tabular}{|c|c|c|}
\hline Range of Movements in Degrees & No. of Patients & $\mathbf{\%}$ \\
\hline Full Range & 28 & 93.33 \\
\hline Mild Restriction & 2 & 6.66 \\
\hline Moderate Restriction & 0 & 0 \\
\hline Severe Restriction & 0 & 0 \\
\hline Total & 30 & 100 \\
\hline Table 1. Range of Movements at 24 Weeks (Degrees) \\
\hline
\end{tabular}

\begin{tabular}{|c|c|c|}
\hline Outcome & No. of Patients (n= 30) & $\mathbf{\%}$ \\
\hline Excellent & 18 & 60.00 \\
\hline Satisfactory & 12 & 40.00 \\
\hline Poor & 0 & 0.00 \\
\hline \multicolumn{2}{|c|}{ Table 2. Functional Outcome with Percentage } \\
\hline
\end{tabular}

\begin{tabular}{|c|c|c|c|c|}
\hline Complications & Minor & Major & Nil & Total \\
\hline No. of Patients & 12 & 0 & 18 & 100 \\
\hline Percentage & 40 & - & 60 & 100 \\
\hline \multicolumn{6}{|c|}{ Table 3. Postoperative Complications } \\
\hline
\end{tabular}

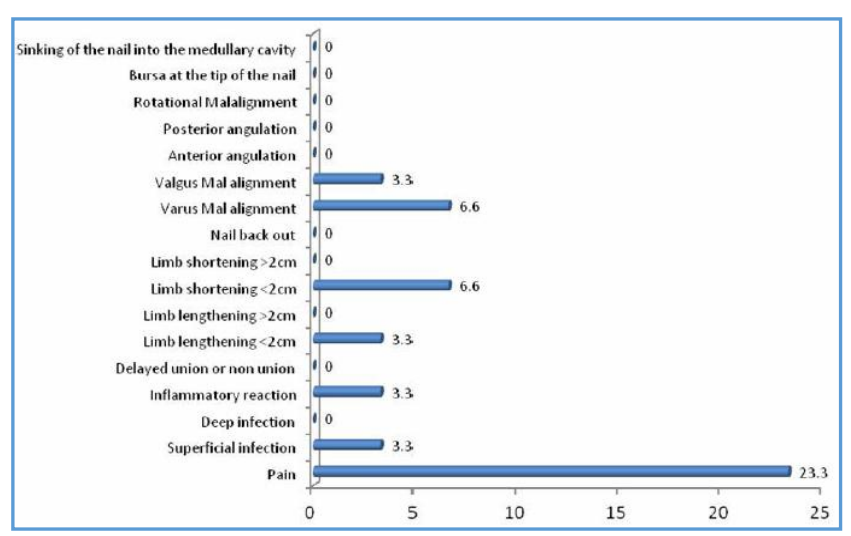

Figure 1. Postop Complications in Graphical Form

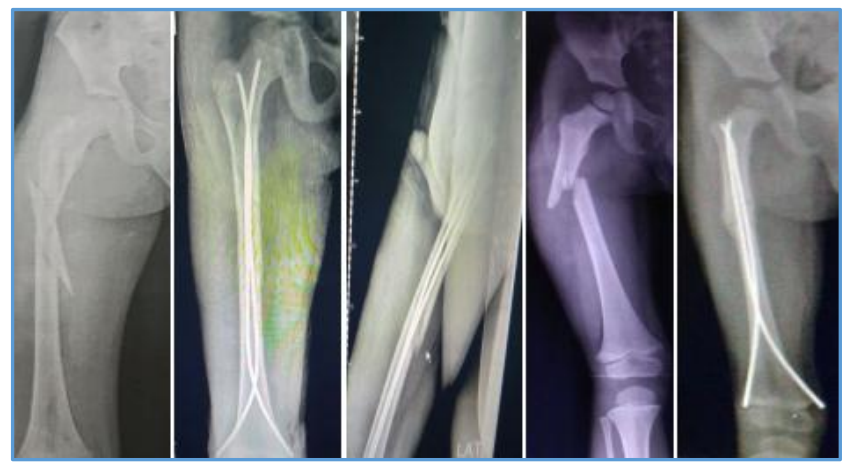

Figure 2. Pre-and Postop X-Rays

\section{DISCUSSION}

In this prospective observational study trauma is a leading cause of morbidity and mortality in children. We had chosen 30 patients, out of that $13(43.3 \%)$ were 4 - 8 years, $7(23.3 \%)$ were 9 to 12 years and $10(33.3 \%)$ were 13 to 16 years' age group with the average age being 9.6 years. There were 9 $(30 \%)$ girls and $21(70 \%)$ boys in the present study. RTA was the most common mode of injury accounting for 16 (53.3\%) cases, self-fall $11(36.7 \%)$ cases and fall from height $3(10 \%)$ cases. Average duration between trauma and surgery was 3.9 days in this study; 21 (70\%) cases were immobilised (long leg cast) postoperatively for 6 weeks followed by active hip and knee mobilisation with non-weight crutch walking. Union was achieved in $<3$ months in $24(80 \%)$ of the patients and $3-4.5$ months in $6(20 \%)$. Average time to union was 12.1 weeks, unsupported walking on full weight bearing was started in $<12$ weeks for $24(80 \%)$ patients between 12 and 18 weeks in $6(16.7 \%)$ patients. The average time of full weight bearing was 11.5 weeks.

Superficial infection was seen in $1(3.3 \%)$ case, which was controlled by antibiotics. All patients had full range of hip and knee motion in the present study and $2(6.66 \%)$ patients had mild restriction in knee flexion at 12 weeks, but normal range of knee flexion was achieved at 16 wks. Nail back out was not seen in any of the cases. Some degree of angular deformity is frequent after femoral shaft fractures in children, but this usually remodels during growth. $2(6.7 \%)$ patients presented with varus angulation, $1(3.3 \%)$ patient presented with valgus angulation and they were within the acceptable limits. No patients had significant antero-posterior and rotational deformity.

In the present study, the final outcome was excellent in 18 (60\%) cases, satisfactory in $12(40 \%)$ cases and there were no poor outcome cases.

\section{CONCLUSION}

Based on the results in our prospective observational study, we conclude that Elastic Stable Intramedullary Nailing technique is an ideal method for treatment of paediatric femoral diaphyseal fractures. It gives elastic mobility promoting rapid union at fractures site and stability which is ideal for early mobilisation. With shorter operative time, lesser blood loss, less radiation exposure, shorter hospital stay and reasonable time to bone healing, it gives lower complication rate, good outcome when compared with other methods of treatment. 


\section{REFERENCES}

[1] Saikia K, Bhuyan S, Battacharya T, et al. Titanium elastic nailing in femoral diaphyseal fractures of children 616yrs of age. Indian J Orthop 2007;41(4):381-5.

[2] Flynn JM, Skaggs D, Sponseller PD, et al. The operative management of pediatric fractures of the lower extremity. J Bone Joint Surg Am 2002;84(12):2288-300.

[3] 3. Buckley SL. Current trends in the treatment of femoral shaft fractures in children and adolescents. Clin Orthop Relat Res 1997;338:60-73.

[4] Bhaskar A. Treatment of long bone fractures in children by flexible titanium elastic nails. Indian J Orthop 2005;39(3):166-8.

[5] Buford D Jr, Christensen K, Weatherall P. Intramedullary nailing of femoral fractures in adolescents. Clin Orthop Relat Res 1998;350:85-9.

[6] Buechsenschuetz KE, Mehlman CT, Shaw KJ, et al. Femoral shaft fractures in children: traction and casting versus elastic stable intramedullary nailing. J Trauma 2002;53(5):914-21.

[7] Gwyn DT, Olney BW, Dart BR, et al. Rotational control of various pediatric femur fractures stabilized with titanium elastic intramedullary nails. J Pediatr Orthop 2004;24(2):172-7.
[8] Metaizeau JP. Stable elastic intramedullary nailing for fractures of the femur in children. J Bone Joint Surg Br 2004;86(7):954-7.

[9] Hunter JB. The principles of elastic stable intramedullary nailing in children. Injury 2005;36(Suppl 1):A20-4.

[10] Narayanan UG, Hyman JE, Wainwright AM, et al. Complications of elastic stable intramedullary nail fixation of pediatric femoral fractures and How to avoid them. J Pediatr Orthop 2004;24(4):363-9.

[11] Flynn JM, Hresko T, Reynolds RA, et al. Titanium elastic nails for pediatric femur fractures: a multicenter study of early results with analysis of complications. J Pediatr Orthop 2001;21(1):4-8.

[12] Heinrich SD, Drvaric DM, Darr K, et al. The operative stabilization of pediatric diaphyseal femur fractures with flexible intramedullary nails: a prospective analysis. J Pediatr Orthop 1994;14(4):501-7.

[13] Heybeli M, Muratli HH, Çelebi L, et al. The results of intramedullary fixation with titanium elastic nails in children with femoral fractures. Acta Orthop Traumatol Turc 2004;38(3):178-87. 